\title{
Effectiveness of physical activity promotion based in primary care: systematic review and meta-analysis of randomised controlled trials
}

\author{
(c) (1) (8) OPEN ACCESS
}

\section{Gillian Orrow academic clinical fellow in general practice, Ann-Louise Kinmonth foundation professor of general practice, Simon Sanderson senior clinical research associate, Stephen Sutton professor of behavioural science}

General Practice and Primary Care Research Unit, Department of Public Health and Primary Care, Institute of Public Health, University of Cambridge, Cambridge CB2 0SR, UK

\begin{abstract}
Objectives To determine whether trials of physical activity promotion based in primary care show sustained effects on physical activity or fitness in sedentary adults, and whether exercise referral interventions are more effective than other interventions.

Design Systematic review and meta-analysis of randomised controlled trials.

Data sources Medline, CINAHL, PsycINFO, EMBASE, SPORTDiscus, Centre for Reviews and Dissemination, the Cochrane Library, and article reference lists.

Review methods Review of randomised controlled trials of physical activity promotion in sedentary adults recruited in primary care, with minimum follow-up of 12 months, reporting physical activity or fitness (or both) as outcomes, and using intention to treat analyses. Two reviewers independently assessed studies for inclusion, appraised risk of bias, and extracted data. Pooled effect sizes were calculated using a random effects model.

Results We included 15 trials $(n=8745)$. Most interventions took place in primary care, included health professionals in delivery, and involved advice or counselling given face to face or by phone (or both) on multiple occasions. Only three trials investigated exercise referral. In 13 trials presenting self reported physical activity, we saw small to medium positive intervention effects at 12 months (odds ratio 1.42, 95\% confidence interval 1.17 to 1.73 ; standardised mean difference 0.25 , 0.11 to 0.38 ). The number needed to treat with an intervention for one additional sedentary adult to meet internationally recommended levels of activity at 12 months was 12 (7 to 33). In four trials reporting cardiorespiratory fitness, a medium positive effect at 12 months was non-significant (standardised mean difference $0.51,-0.18$ to 1.20). Three trials of exercise referral found small non-significant effects on self
\end{abstract}

reported physical activity at 12 months (odds ratio $1.38 ; 0.98$ to 1.95 ; standardised mean difference $0.20,-0.21$ to 0.61 ).

Conclusions Promotion of physical activity to sedentary adults recruited in primary care significantly increases physical activity levels at 12 months, as measured by self report. We found insufficient evidence to recommend exercise referral schemes over advice or counselling interventions. Primary care commissioners should consider these findings while awaiting further trial evaluation of exercise referral schemes and other primary care interventions, with longer follow-up and use of objective measures of outcome.

\section{Introduction}

The United Kingdom's chief medical officers recommend that adults undertake at least 150 minutes of moderate intensity activity each week. ${ }^{1}$ Self reported achievement of these activity levels was associated with a $19 \%$ reduction in the rate of all cause mortality, compared with sedentary behaviour, in a large meta-analysis of cohort studies. ${ }^{2}$ Yet only $39 \%$ of men and $29 \%$ of women achieved these levels in the 2008 Health Survey for England. ${ }^{3}$ Primary care is well placed to promote physical activity among sedentary adults. ${ }^{45}$ In developed countries, $70-80 \%$ of adults visit their general practitioner at least once a year, ${ }^{6}$ and patients are interested in discussing health promotion issues with primary care health professionals. ${ }^{7}$

Interventions to promote smoking cessation and alcohol reduction in primary care have shown effectiveness ${ }^{89}$ and have been recognised as important preventive activities. ${ }^{10}{ }^{11}$ Evidence to support physical activity promotion in primary care is less robust. Previous reviews have been limited by the inclusion of non-randomised trials and trials with short follow-up duration. ${ }^{12-15}$ Assessing the sustainability of impact of interventions is important, because observational research shows 
that the health benefits of physical activity are lost with reversion to a sedentary lifestyle. ${ }^{16} \mathrm{~A}$ Cochrane systematic review of interventions to promote physical activity in community dwelling adults showed a moderate effect on self reported physical activity and cardiorespiratory fitness at a minimum of six months of follow-up. ${ }^{17}$ However, these findings might not be directly generalisable to the primary care setting, since half of the included studies recruited participants from alternative sources. Furthermore, several large trials of physical activity promotion based in primary care have reported outcomes with at least 12 months' follow-up since this systematic review was undertaken. ${ }^{18-23}$

Physical activity can be promoted in primary care in different ways, including delivery of advice, provision of written materials, and referral to an exercise programme. The UK has seen a marked expansion in exercise referral schemes over the past two decades, ${ }^{24}$ but there are concerns that these might not produce sustained changes in physical activity beyond the typical programme length of 12 weeks. ${ }^{25}$ In 2006, the UK National Institute for Health and Clinical Excellence (NICE) advised that exercise referral schemes should not be commissioned in primary care outside of well designed research studies. Despite this recommendation, the schemes remain widely used and a reappraisal of the evidence, five years since the NICE guidelines were published, is indicated to inform primary care clinicians and commissioners.

We did a systematic review and meta-analysis of randomised controlled trials of primary-care based physical activity promotion for sedentary adults with minimum 12 months follow-up. We had two objectives, to determine whether such trials showed sustained effects on physical activity or fitness in sedentary adults, and whether exercise referral interventions were more effective than other interventions.

\section{Methods}

\section{Eligibility criteria}

Included trials met eight criteria:

1) Participants: adults aged 16 years or over, and determined as sedentary during participant recruitment or baseline measurement at trial entry

2) Recruitment: through primary care (that is, recruited from patients attending or registered with a general practice, family practice, or primary care clinic)

3) Intervention: any intervention of physical activity promotion, provided that the primary stated goal was to increase activity or fitness levels (or both) in participants (we excluded studies examining multifactorial interventions, such as promoting dietary modification in addition to physical activity)
4) Comparator characteristics: no restrictions
5) Outcome: physical activity or fitness
6) Design: randomised controlled trial
7) Follow-up: minimum of 12 months after randomisation
8) Analysis: intention to treat.

\section{Search methods, study selection, and data extraction}

We searched seven electronic databases: Medline, CINAHL, PsycINFO, Embase, SPORTDiscus, Centre for Reviews and Dissemination, and the Cochrane Library (May 2009; repeated May 2010). The search strategy included terms for "physical activity", "primary care", and "randomised controlled trial" (web appendix). We adapted the search for each database without language or date restrictions. We also hand searched reference lists of relevant articles and previous systematic reviews and contacted an independent expert to check omissions. Titles and abstracts were screened against inclusion criteria by GO and potentially eligible articles were retrieved. Two reviewers (GO and $\mathrm{SSu}$ ) assessed retrieved papers independently. A third reviewer (ALK) resolved any conflicts. GO and SSu extracted data independently for each included paper onto a piloted form including: year and study location; recruitment method; participant flow; risk of bias; participant, intervention, and comparator characteristics; frequency and intensity of outcome measurement; and data on self reported and objective physical activity, cardiorespiratory fitness, and adverse events. We obtained further information from authors of nine studies, ${ }^{18} 2126-32$. This related mainly to assessment of risk of bias. We obtained unpublished data from one author. ${ }^{18}$

\section{Classification of intervention or control type}

GO and SSu classified intervention and control types independently. In our main analysis, we considered all types of interventions of physical activity promotion. Our secondary analysis focused on exercise referral interventions, defined as "any intervention where a patient is referred from primary care for a programme of physical exercise. The programme may be community-based (for example health walks) or facility-based (for example fitness classes). The intervention will usually include counselling measures of variable intensity".

Control interventions were classified as a "comparator intervention" if control participants received any type of physical activity promotion intervention during the trial, and as "no intervention" if they did not.

\section{Risk of bias assessment}

GO and SSu appraised each study independently for risk of bias, using accepted guidance. ${ }^{33} \mathrm{We}$ considered the following domains: sequence generation, allocation concealment, blinding of study personnel and participants, incomplete outcome data, and selective outcome reporting. For each domain, we examined each paper's description of methods and made a judgment regarding potential bias, according to three categories: low risk, high risk, or risk unclear. We also created funnel plots using RevMan software to assess risk of publication bias for the set of studies.

\section{Statistical analysis Effect size calculation}

Intervention effects at 12 months (or the nearest time point thereafter, if 12 month data were not supplied) were calculated for each study for physical activity or fitness (or both). We calculated odds ratios and standardised mean differences with 95\% confidence intervals using RevMan for studies with dichotomous and continuous outcome data, respectively.

If a study presented both a trial completers' analysis and a full intention to treat analysis using imputed values, we used the intention to treat analysis. If more than one variable for self reported physical activity was available, we selected the variable that best reflected total activity. If no measure of total reported activity was available, we selected the outcome measure most similar to that provided in other studies. If a study included more than one intervention group, we summarised the results across all intervention groups by pooling their means and 
standard deviations according to standard methods. ${ }^{34}$ We used the same method to combine results if data were presented separately for men and women.

If standard deviations at follow-up were not supplied, we carried forward the baseline values. If the studies only reported medians, ${ }^{21}{ }^{35}{ }^{36}$ we treated these values as means, and calculated standard deviations from interquartile ranges (using the formula: standard deviation=interquartile range/1.35). The author of one study did provide unpublished means and standard deviations, but these values were based on skewed data. ${ }^{18}$ We adjusted for clustering in two studies ${ }^{18}{ }^{29}$ by calculating the effective sample size. ${ }^{37} \mathrm{We}$ used the intraclass correlation coefficient of 0.05 , as published by Elley and colleagues,$^{29}$ for both studies because the other study ${ }^{18}$ did not supply a coefficient value.

\section{Result synthesis}

Five prespecified meta-analyses were conducted using a random effects model in RevMan. We calculated pooled effect estimates for self reported physical activity (for dichotomous and continuous data separately) and fitness (continuous data only) including all trials in which these outcomes were reported. Further pooled estimates were calculated for self reported physical activity (for dichotomous and continuous data separately) for the subset of trials of exercise referral schemes. For each analysis, we calculated the $\mathrm{I}^{2}$ statistic to estimate the proportion of the observed variance in effects across studies that indicates real differences rather than random error, with $95 \%$ confidence intervals using Stata. We used values of $25 \%$, $50 \%$, and $75 \%$ as boundary limits for low, moderate, and high heterogeneity. ${ }^{38}$ To calculate the number needed to treat for one additional sedentary adult to meet recognised physical activity recommendations with $95 \%$ confidence intervals, we used the formula [CER(odds ratio-1)+1]/[CER(odds ratio-1) $\times(1-\mathrm{CER})]$ (where $\mathrm{CER}=$ control event rate) and the pooled odds ratio for those nine studies in which this outcome was reported. ${ }^{39}$

\section{Subgroup, sensitivity, and additional analyses}

We conducted a subgroup analysis to compare the estimates of intervention effect on self reported physical activity in trials that used no intervention controls with those in trials that used comparator controls. A similar analysis was not possible for cardiorespiratory fitness because all the trials that reported this outcome used comparator controls.

Sensitivity analyses explored effects of decisions about outcome selection and design effects. These analyses were planned after data extraction but before undertaking the meta-analyses.

We also calculated the change in percentage of participants in intervention, comparator control, and no intervention control groups who reached target levels of physical activity between baseline and 12 month follow-up (or the nearest time point thereafter) for each study in which these data were available. This exploratory analysis was planned after data extraction.

\section{Results}

\section{Study selection}

We included 16 papers referring to 15 separate randomised controlled trials after screening 8271 titles and abstracts and reviewing 61 full texts (fig $1 \Downarrow$ ). Funnel plots did not display overt asymmetry that would suggest publication bias (fig $2 \Downarrow$ ).

\section{Study and participant characteristics}

In 15 trials, 8745 participants aged between 17 and 92 years were randomised. Fourteen trials reported the proportion of those randomised out of the total number approached (8461 (22.6\%) of 37496 ) (table $1 \Downarrow$ ). Of those participants approached but not randomised, six trials specified how many were excluded because they were already active (5051 (37\%) of 13 647). Just over half of participants were female (54\%; table 1). In all trials but one, participants were recruited in person in primary care, by written invitation or by telephone. In one study, trial participants were patients who had been referred by their primary care health professional to an exercise referral scheme. ${ }^{20} \mathrm{Six}$ trials took place in the UK, three in New Zealand, two in the United States, and one each in Switzerland, the Netherlands, Australia, and Canada.

In four trials, participants were selected for adverse vascular risk or cardiovascular disease $;^{18} 202732$ in the remaining trials, participants were from general primary care populations. Most studies selected participants for sedentary behaviour, but the percentage meeting recommended guidelines for physical activity at baseline ranged from $0 \%^{19}{ }^{20}$ to $44 \%^{18}$ in the nine studies reporting this outcome. Educational achievement also varied widely, when reported (10 trials). Where ethnic origin was reported (eight trials), at least two thirds of participants were white or European. Information about the socioeconomic and employment status of study participants was missing in two thirds of the studies. All studies reported outcome data at 12 months after randomisation, apart from one ${ }^{19}$ reporting at 14 months, and another ${ }^{28}$ reporting at 24 months.

\section{Intervention characteristics}

A wide range of interventions was studied (table $2 \Downarrow$ ). Physical activity promotion was delivered in primary care in 10 studies, in primary care and a sports facility in one study, and at home or by telephone only in two studies. In one further study where intervention delivery took place in a sports facility, participants were recruited after referral from primary care. One study did not specify the setting for intervention delivery.

Most interventions included written materials and two or more sessions of advice or counselling on physical activity, delivered face to face. In nine studies, supplementary advice or counselling was delivered by telephone, and in one trial, the intervention was delivered exclusively by telephone. Another trial provided automatic telephone messages in addition to face to face, telephone, and written contacts. Advice or counselling was delivered by a combination of two professionals from different disciplines in most studies.

Primary care doctors or nurses were involved in eight studies; physiotherapists in two studies; and health visitors, health educators, health counsellors, health promotion specialists, or trained facilitators from a range of health professions in a further five studies. Exercise or physical activity specialists or counsellors were involved in intervention delivery in seven studies, and in four of these studies this accompanied input from a primary care doctor or nurse, with referral from a primary care doctor or nurse before randomisation in a fifth study.

Of the three exercise referral studies, one involved referral to a leisure centre based programme, one to a community walks programme, and one involved small group exercise sessions at an unspecified location. Five studies offered participants self monitoring tools and three studies provided a personalised written exercise prescription. Ten studies specified the theory underlying intervention design; motivational interviewing and 
the transtheoretical model of behaviour change were specified most frequently.

\section{Control interventions}

Seven control groups met our definition of "no intervention", of which one involved the promotion of "good nutrition". ${ }^{35}$ Eight studies used a comparator intervention (table 2). In six of these studies, primary care was the setting for intervention delivery, and in two, control participants received mailed information only on the benefits of physical activity. In five studies, control participants received one to one advice to increase their physical activity and, in one study, advice was group based. Advice was delivered by a primary care doctor or nurse in three studies, by a primary care doctor and a health educator in one study, and by a researcher or a physiotherapist in two studies. Intervention delivery took place on one occasion only in seven of the eight comparator control interventions. Only one trial specified a theoretical approach underpinning the comparator control intervention.

\section{Risk of bias}

All studies but two were judged to be at high risk of bias in at least one domain (table $3 \Downarrow$ ). None of the studies was judged to be at high risk of selection bias. Blinding of participants to study group allocation was achieved in one study, not achieved in one, not reported in seven, and not possible in six (in which control participants received no intervention). Because self reported physical activity was the main outcome measure in most studies, failure to blind participants to allocation might have resulted in differential effects of social desirability bias between participants allocated to intervention and those allocated to control. Trial personnel or outcome assessors were not blinded to allocation in five studies, and management of incomplete outcome data led to high risk of bias in six studies. One study reported outcomes selectively (a planned analysis of cardiorespiratory fitness was not reported owing to concerns over inaccuracies in study data). ${ }^{21}$ Risk of bias was judged to be unclear in at least one domain for nine studies.

\section{Self reported physical activity}

Data for self reported physical activity were collected in 14 studies using various assessment tools, including questionnaires or logbooks either self administered or administered by an interviewer (table $4 \Downarrow$ ). In nine studies, dichotomous outcome measures related to whether participants had achieved a specified target level of physical activity in keeping with accepted guidelines (most commonly the achievement of at least 30 minutes of moderate intensity activity each day for at least five days per week). ${ }^{18-23} 282936$ In two studies, they related to whether participants had increased their level of physical activity from baseline. $^{26} 27$

For continuous outcome measures, five studies converted self reported data into total physical activity in minutes per week $^{18} 21-2336$; two to total energy expenditure in $\mathrm{kcal} / \mathrm{kg}$ per week $;^{29}{ }^{30}$ and one to total activity as a metabolic equivalent in $\mathrm{h} / \mathrm{week}^{32}$ Two studies reported frequency of activity, one as walking in sessions per week, ${ }^{35}$ and another as change in frequency of exercising for at least 20 minutes in the previous four weeks, compared with baseline. ${ }^{27}$

\section{Intervention effects on self reported physical activity}

Eleven studies reported positive intervention effects on self reported physical activity at 12 months; these effects were significant in six studies. Pooled analysis of 13 studies showed small to medium effects for dichotomous data (odds ratio 1.42 (95\% confidence interval 1.17 to 1.73 ); $\mathrm{I}^{2}=43 \%$ ( $0 \%$ to $70 \%$ ); fig $3 \Downarrow$ ) and continuous data (standardised mean difference 0.25 ( 0.11 to 0.38 ); $I^{2}=70 \%$ ( $27 \%$ to $83 \%$ ); fig $4 \Downarrow$ ). The wide confidence intervals for $\mathrm{I}^{2}$ indicate uncertainty about the true degree of heterogeneity. One study presented mean percentage change in self reported physical activity at 12 months as geometric means only. ${ }^{30}$ Our meta-analysis used arithmetic means and because we were unable to calculate the arithmetic means for self reported physical activity at 12 months for this study using the available data, we could not include it in the pooled analysis. This study found no significant intervention effect on self reported physical activity at 12 months. ${ }^{30}$

The number needed to treat with an intervention of physical activity promotion, compared with any control, for one additional sedentary adult to report meeting recommended levels of physical activity at 12 months was 12 (95\% confidence interval 7 to 33 ), based on the pooled odds ratio for the nine studies that reported this outcome. . $^{1-23} 282936$

\section{Intervention effects on objective physical activity}

Only one study reported an objective measure of physical activity in all participants. ${ }^{32}$ The mean intervention effect for this measure (after adjustment for baseline measurement and minimisation stratifiers) was not significant at 12 month follow-up ( -0.04 (95\% confidence interval -0.16 to 0.08$)$ ).

\section{Intervention effects on cardiorespiratory fitness}

Four studies reported cardiorespiratory fitness. Three studies reported $\mathrm{VO}_{2} \mathrm{max}$ in $\mathrm{mL} / \mathrm{min},{ }^{28} \mathrm{~mL} / \mathrm{kg}$ per minute, ${ }^{31}$ or $\mathrm{L} / \mathrm{min},{ }^{32}$ and one study reported aerobic capacity as L/min. ${ }^{36}$ Only one study showed a significant intervention effect. ${ }^{31}$ The pooled standardised mean difference had a medium effect size but was non-significant $(0.51$ (95\% confidence interval -0.18 to 1.20$)$; fig $5 \Downarrow)$. Heterogeneity was high $\left(\mathrm{I}^{2}=97 \%(96 \%\right.$ to $98 \%)$ ), and a sensitivity analysis showed that this was attributable to one outlying study with strong positive results, ${ }^{31}$ without which heterogeneity was low $\left(I^{2}=0 \%\right)$.

\section{Intervention effects of exercise referral interventions}

Three studies examined exercise referral interventions. ${ }^{2027}{ }^{26}$ In one study, ${ }^{27}$ the exercise referral intervention was one of three intervention groups and was compared to a no intervention control. The other two studies used comparator controls. ${ }^{20}{ }^{36}$ No study found a significant effect on self reported physical activity at 12 months. Pooled analysis showed small, non-significant effects on self reported physical activity at 12 months (odds ratio 1.38 (95\% confidence interval 0.98 to 1.95$), \mathrm{I}^{2}=0 \%$ ( $0 \%$ to $73 \%)$; standardised mean difference $0.20(-0.21$ to 0.61$)$, $\mathrm{I}^{2}=76 \%$ ) (figs $6 \Downarrow$ and $7 \Downarrow$ ). One study also reported no effect on cardiorespiratory fitness at 12 months. ${ }^{36}$

\section{Adverse events}

Adverse events varied substantially among the six trials that reported them. Only one study found a significant intervention effect on adverse events, reporting a relative $11 \%$ increase in falls and a $6 \%$ increase in injuries among intervention participants between baseline and 12 months' follow-up, compared with control participants. ${ }^{21}$ 


\section{Subgroup and sensitivity analyses}

In the six studies that compared physical activity promotion to no intervention, we saw a medium, positive, and significant intervention effect on self reported physical activity at 12 months (odds ratio 1.74 (95\% confidence interval 1.39 to 2.18 ), $\mathrm{I}^{2}=21 \%$ ( $0 \%$ to $71 \%)$; standardised mean difference 0.36 ( 0.28 to 0.43$)$, $\mathrm{I}^{2}=0 \%\left(\mathrm{I}^{2} 0 \%\right.$ to $\left.61 \%\right)$ ). In the seven studies that compared interventions with comparator interventions, we did not see a significant effect on self reported physical activity at 12 months (odds ratio 1.18 (0.95 to 1.48$), \mathrm{I}^{2}=9 \%$ ( $0 \%$ to $\left.64 \%\right)$; standardised mean difference -0.03 ( -0.17 to 0.11$), \mathrm{I}^{2}=0 \%$ ( $0 \%$ to $\left.73 \%\right)$ ). For both dichotomous and continuous data, we found significant differences in effect size between these two sets of studies (dichotomous data, $\chi^{2}=6.9 \mathrm{df}=1, \mathrm{P}=0.008$; continuous data, $\left.\chi^{2}=21.7, \mathrm{df}=1, \mathrm{P}<0.00001\right)$.

In the meta-analyses on self reported physical activity (fig 3 ), after removal of data from three studies presenting non-parametric data and from one study with supplied means based on skewed data, ${ }^{182} 3536$ the pooled effect estimates increased (odds ratio 1.50 (1.22 to 1.84$), \mathrm{I}^{2}=16 \%$ ( $0 \%$ to $63 \%$ ); standardised mean difference 0.28 ( 0.12 to 0.44$), \mathrm{I}^{2}=57 \%$ ( $0 \%$ to $82 \%)$ ). In the meta-analysis of continuous physical activity data (fig 4), removal of two studies that did not present an outcome measure for total activity reduced the pooled effect estimate but did not affect the direction or significance of the findings (standardised mean difference 0.20 (0.05 to 0.35), $\mathrm{I}^{2}=72 \%(18 \%$ to $\left.85 \%)\right)$.

\section{Change in physical activity over time}

Nine studies reported the proportion of participants meeting recommended levels of physical activity at baseline and 12 months (or at the next available time point, if 12 month data were not available). Figure $8 \Downarrow$ shows the change in percentage of participants meeting these recommendations over this period by intervention and type of control group. The increase seen in participants randomly assigned to receive a comparator intervention was almost as large as that seen in participants assigned to receive an intervention. We saw a much smaller increase in participants allocated to receive no intervention, than in those allocated to receive an intervention.

\section{Discussion}

\section{Summary and interpretation of findings}

In this systematic review, we found that promotion of physical activity to sedentary adults identified through primary care leads to a small to medium improvement in self reported physical activity at 12 months (odds ratio 1.42 (95\% confidence interval 1.17 to 1.73 ); standardised mean difference 0.25 ( 0.11 to 0.38 )). The best estimate of the number needed to treat for one additional sedentary adult to report recommended levels of activity at 12 months is 12 . Only four trials reported cardiorespiratory fitness and pooled analysis showed no significant effect. One study reported objective physical activity and also found no significant effect. In most studies, interventions included written materials and advice or counselling delivered in person or by telephone on multiple occasions by health professionals in primary care. Only three trials studied exercise referral interventions, and pooled analysis showed small non-significant effects on self reported physical activity at 12 months. Five of six trials reporting adverse events identified no increase associated with physical activity promotion.
A planned subgroup analysis showed significantly larger intervention effects on self reported activity in studies where control participants received no intervention than where they received a comparator intervention. A further exploratory analysis suggested that a possible reason why results differed according to control type used was that comparator interventions themselves affected self reported physical activity. The additional percentage of participants who reported meeting international activity recommendations at 12 months, compared with baseline, was $11-47 \%$ in participants allocated to receive an intervention, and $8-47 \%$ in those allocated to receive a comparator intervention. The corresponding range for those allocated to receive no intervention was from $-2 \%$ to $+19 \%$ (fig 8). These findings suggest that briefer interventions, as used in the comparator groups, might achieve effects that are similar to those of more intensive interventions.

Further support for this hypothesis was seen in the findings of four studies included in this review that examined two or more interventions of incremental intensity. These studies found no significant difference in self reported or objective physical activity at one year follow-up ${ }^{2627} 32$ or cardiorespiratory fitness at two year follow-up ${ }^{28}$ between participants in intervention arms of different intensity. Alternatively, social desirability bias could explain why control participants who received an intervention reported more activity at 12 months than those who received no intervention.

We found no effect of interventions on cardiorespiratory fitness at 12 months across four trials, by contrast with the systematic review by Hillsdon and colleagues, which identified a positive effect on fitness at a minimum of six month follow-up. ${ }^{17}$ This absence of effect could have been due to the small number of studies recruiting through primary care that reported fitness data, three of which also found no significant effect on self reported physical activity. The effect sizes showed high heterogeneity, and sensitivity analyses suggested that this was attributable to one outlying study with strong positive findings. ${ }^{31}$ The intervention used in this study was unique in including prescription of an exercise training heart rate.

We found small, non-significant effects of exercise referral interventions on self reported physical activity at 12 months across three studies. The effects only narrowly missed statistical significance for dichotomous data. In interpreting these findings, it is informative to examine the nature of the comparator interventions used.

One study compared exercise referral with physical activity advice delivered in a group. At 12 months, researchers saw no difference in self reported activity, measured as a continuous variable (total amount of moderate intensity activity), or fitness between groups, but did find a small, non-significant increase in activity measured as a dichotomous variable (proportion meeting activity recommendations). ${ }^{36}$

A second study compared exercise referral with written information about physical activity and found small non-significant effects on self reported activity at 12 months. ${ }^{20}$ A third study used a no intervention control, and found small to medium sized positive effects on self reported activity, which were significant for continuous (frequency of exercise sessions) but not dichotomous data (proportion of participants who had become more active from study entry) ${ }^{27}$ In summary, although no significant pooled effect was found, in individual studies, the likelihood of meaningful effect was highest in the comparison of exercise referral schemes with no intervention and weakest for the comparison of exercise referral schemes with advice given face to face. These findings are consistent 
with those reported by Pavey and colleagues in their systematic review and meta-analysis of exercise referral schemes. ${ }^{40}$ They found a $16 \%$ increase in the relative risk of achieving recommended levels of physical activity at six to 12 months with exercise referral schemes compared with usual care, but no significant difference between exercise referral schemes and alternative physical activity interventions.

Whether or not exercise referral schemes are more effective than advice, the benefits of exercise referral schemes could be argued to extend beyond making patients more active.

Aspirations for weight loss or improvements in mood are two popular reasons for patients or clinicians to choose an exercise referral scheme. Focusing on the outcome of physical activity or fitness alone could miss these and other important benefits. However, observational evidence suggests that long term improvements in cardiovascular health depend on sustained changes in physical activity ${ }^{16}$ and the same may be expected to be true for long term improvements in weight and mental health.

\section{Strengths and limitations}

Our review has several strengths. To our knowledge, it is the first to examine the effect of physical activity promotion over at least 12 months in patients recruited in primary care. Most studied interventions were delivered in primary care by health professionals. Where exercise professionals were involved, their input did not extend beyond that seen in implemented primary care programmes such as exercise referral schemes in the UK or the "Green Prescription" programme in New Zealand. Two fifths of included studies were conducted in the UK and most of the remaining trials took place in countries with broadly comparable primary care services, enhancing the generalisability of our findings to these settings.

Our findings extend the evidence from two previous systematic reviews of community based interventions ${ }^{17}{ }^{41}$ in two ways.

Firstly, we included only studies recruiting through primary care to more directly inform commissioning in general practice. Secondly, we included studies with longer follow-up to inform sustainability of effect. Eight of the studies in our review were not included in these previous reviews. Our results also highlight that brief comparator interventions used in physical activity trials could have similar effects to the interventions to which they are compared. We reduced risk of bias present in other reviews ${ }^{13} 14$ by including only randomised controlled trials.

Our review is affected by several limitations at the study level including, most importantly, the use of self reported measures of physical activity as the main outcome measure in most included trials. It is difficult to conceal the study group from participants in physical activity trials, and self reported measures are therefore susceptible to differential social desirability bias, which could inflate estimates of intervention effect. Self reported measures of physical activity also lack precision and our findings would have been strengthened if complemented by greater use of objective measures.

The strength of our conclusions was reduced further by other trial factors that might have introduced bias in two thirds of studies. Trial personnel or outcome assessors were not blinded to allocation in five studies, and management of incomplete outcome data was inadequate in six studies. Generally, such factors would be expected to lead to bias in the direction of overestimating the effect of the intervention. A possible exception is incomplete outcome data which could lead to underestimation of the intervention effect in some circumstances (for example, if a proportion of intervention participants leave the study because they have increased their physical activity).
Reporting of the content of interventions was often poor, especially in relation to intensity and fidelity of intervention delivery. Improved clarity here, and possibly reference to taxonomies of behavioural interventions,${ }^{43}$ would have facilitated interpretations about the effective components of interventions. When reported, most trial participants were white, and socioeconomic characteristics were poorly reported; therefore, we do not know whether our findings apply to adults with different ethnic, social, and economic characteristics.

Furthermore, participants in the included trials could have been more motivated to increase their physical activity than the primary care populations from which they were recruited.

At a review level, our search was systematic but we did not identify any unpublished trials. The funnel plots did not suggest publication bias, although these plots are difficult to interpret with a small number of studies. Only one reviewer screened titles and abstracts, and although papers could have been missed at this stage, seven databases were systematically searched on two occasions (May 2009; repeated May 2010), supplemented by hand searching of reference lists. Furthermore, no additional studies were identified by an independent expert on the topic.

Our meta-analysis included trials that supplied non-parametric data, to estimate effects across the largest possible number of eligible trials. Removal of these data in a sensitivity analysis led to an increase in the pooled intervention effect on self reported physical activity that retained statistical significance, suggesting that the decision to include these studies in the main analysis led, at worst, to an underestimation of the pooled intervention effect. Finally, since follow-up was limited to 12 months in most trials, we could not assess the effect of interventions on clinical outcomes, such as incidence of diabetes mellitus, cardiovascular events, or mortality. Assessment of other potentially beneficial effects of physical activity promotion, including the effect on psychological outcomes or self rated health, was also beyond the scope of our review.

\section{Conclusions and implications for policy, practice, and research}

Our review shows the effectiveness over at least 12 months of interventions to promote physical activity based in primary care. The best estimate of the number needed to treat with a physical activity promotion intervention for one additional sedentary adult to report recommended levels of activity at 12 months was 12 , which compares favourably to the estimated numbers needed to treat of 50-120 for smoking cessation advice. ${ }^{8}$ Based on the findings of a meta-analysis of cohort studies including almost one million individuals, achievement of these activity levels in populations with low levels of activity could reduce mortality by about one fifth. ${ }^{2}$ Cost effectiveness was not assessed in this review, but recent research suggests that most physical activity interventions based in primary care have comparable cost effectiveness to funded pharmaceutical interventions. ${ }^{44}$

However, these projections of potential benefit of such physical activity promotion must be interpreted with caution, owing to the limitations of self reported measurement of physical activity. Future physical activity promotion trials in primary care should include objective outcome measures of activity and fitness, to increase precision and reduce bias in the estimates of intervention effects. Improved description of study methods, intervention components, and participant characteristics, and longer and more complete follow-up of participants with better reporting of adverse events, would also improve the interpretation of future trials. 
Our review highlights the continuing paucity of evidence on the medium to long term effectiveness of exercise referral schemes. Based on the limited data available, there is no evidence that they are more effective than physical activity advice or counselling. Five years after NICE recommended that exercise referral interventions should not be commissioned in primary care outside of well designed research studies, ${ }^{45}$ we found insufficient evidence to challenge this guidance. This finding is particularly pertinent for general practitioners and commissioners in the current economic climate. Cost per quality adjusted life year has been shown to be higher for exercise referral programmes of supervised exercise classes based in the gym or instructor led walks than for other types of physical activity interventions in primary care. ${ }^{44}$ Further trials of exercise referral are needed, with longer follow-up and objective outcome measures.

Although all the interventions in our review are potentially reproducible in real life settings in primary care, most involved multiple contacts over time. Our findings raise the question of whether brief single contact interventions delivered in primary care can be as effective as more intensive approaches, including exercise referral schemes. Brief interventions have shown effectiveness in the promotion of smoking cessation and alcohol reduction, ${ }^{8}$ and further research is warranted to assess their effectiveness for physical activity promotion.

We thank Julian Higgins for his statistical advice relating to methods used in the meta-analysis, Melvyn Hillsdon for his advice on trials eligible for inclusion in our review, and the authors of primary studies included in our review who responded to requests for clarification or further information about study data.

Contributors: GO, ALK, and SSa contributed to the design of the review. GO executed the search strategy, screened the initial results of the literature searches, drafted the manuscript, and is guarantor of the study. GO and SSu assessed studies for inclusion, appraised and extracted data from the included studies, and undertook statistical analysis. GO, ALK, and SSu interpreted the findings. All authors contributed to the critical revision of the manuscript and approved the final version.

Funding: GO is funded by an academic clinical fellowship from the National Institute for Health Research (NIHR) at the UK Department of Health. ALK is funded by the University of Cambridge and is an NIHR senior investigator. SSu's contribution to the study was funded by an NIHR Programme Grant for Applied Research (RP-PG-0608-10079). SSa's contribution was funded by the NIHR School for Primary Care Research.

Competing interests: All authors have completed the Unified Competing Interest form at www.icmje.org/coi disclosure.pdf (available on request from the corresponding author) and declare: support for the submitted work from the NIHR and University of Cambridge; no financial relationships with commercial entities that might have an interest in the submitted work; no other relationships or activities that could appear to have influenced the submitted work other than their involvement in current primary research in the topic area of the systematic review (ALK, $\mathrm{SSu}$, and GO) and clinical practice in primary care (GO) (ALK is principal investigator of the MRC ProActive trial, SSu and ALK are involved in NIHR funded research on brief interventions to promote physical activity (RP-PG-0608-10079), GO is a clinician in a general practice that uses exercise referral schemes).

Ethical approval: Not required.

Data sharing: No additional data available.

Chief medical officers of England, Scotland, Wales and Northern Island. Start active, stay active: a report on physical activity from the four home countries' chief medical officers. Department of Health, 2011.
2 Woodcock J, Franco OH, Orsini N, Roberts I. Non-vigorous physical activity and all-cause mortality: systematic review and meta-analysis of cohort studies. Int $\mathrm{J}$ Epidemiol 2011:40:121-38.

3 Joint Health Surveys Unit. Health survey for England 2008. Physical activity and fitness. The Stationery Office, 2009.

4 Craig A, Dinan S, Smith A, Taylor A, Webborn N. The National Quality Assurance Framework for Exercise Referral Systems. Department of Health, 2001.

5 Williams NH. "The wise, for cure, on exercise depend": physical activity interventions in primary care in Wales. Br J Sports Med 2009;43:106-8.

6 Van Doorslaer E, Masseria C, Koolman X, for the OECD Health Equity Research Group. Inequalities in access to medical care by income in developed countries. CMAJ 2006;174:177-83.

7 Stott NC, Pill RM. "Advise yes, dictate no." Patients' views on health promotion in the consultation. Fam Pract 1990;7:125-31.

8 Stead LF, Bergson G, Lancaster T. Physician advice for smoking cessation. Cochrane Database Syst Rev 2008;2:CD000165.

9 Kaner EF, Beyer F, Dickinson HO, Pienaar E, Campbell F, Schlesinger C, et al. Effectiveness of brief alcohol interventions in primary care populations. Cochrane Database Syst Rev 2007;2:CD004148.

10 Cardone A, Clancy L, Hering T, Zatonski W, eds. EQUIPP: Europe quitting progress and pathways. Bridgehead International, 2011.

11 Department of Health. Directions from the secretary of state: the Primary Medical Services (Direct Enhanced Services) (England) directions 2010. Department of Health, 2010.

12 Eaton $\mathrm{CB}$, Menard LM. A systematic review of physical activity promotion in primary care office settings. Br J Sports Med 1998;32:11-6.

13 Riddoch C, Puig-Ribera A, Cooper A. Effectiveness of physical activity promotion schemes in primary care: a review. Health Education Authority, 1998

14 Eakin EG, Glasgow RE, Riley KM. Review of primary care-based physical activity intervention studies: effectiveness and implications for practice and future research. $J$ Fam Pract 2000;49:158-68.

15 Smith BJ. Promotion of physical activity in primary health care: update of the evidence on interventions. J Sci Med Sport 2004;7(suppl 1):67-73.

16 Paffenbarger RS Jr, Wing AL, Hyde RT. Physical activity as an index of heart attack risk in college alumni. Am J Epidemiol 1978;108:161-75.

17 Hillsdon M, Foster C, Thorogood M. Interventions for promoting physical activity. Cochrane Database Syst Rev 2005;1:CD003180.

18 Van Sluijs EM, van Poppel MN, Twisk JW, Chin APM, Calfas KJ, van MW. Effect of a tailored physical activity intervention delivered in general practice settings: results of a randomized controlled trial. Am J Public Health 2005;9510:1825-31.

19 Jimmy G, Martin BW. Implementation and effectiveness of a primary care based physical activity counselling scheme. Patient Educ Couns 2005;56:323-31.

20 Harrison RA, Roberts C, Elton PJ. Does primary care referral to an exercise programme increase physical activity one year later? A randomized controlled trial. $J$ Public Health 2004;271:25-32.

21 Lawton BA, Rose SB, Elley CR, Dowell AC, Fenton A, Moyes SA. Exercise on prescription for women aged 40-74 recruited through primary care: two year randomised controlled trial. BMJ 2008;337:a2509

22 Kolt GS, Schofield GM, Kerse N, Garrett N, Oliver M. Effect of telephone counseling on physical activity for low-active older people in primary care: a randomized, controlled trial. J Am Geriatr Soc 2007;55:986-92.

23 Morey MC, Peterson MJ, Pieper CF, Sloane R, Crowley GM, Cowper PA, et al. The Veterans Learning to Improve Fitness and Function in Elders Study: a randomized trial of primary care-based physical activity counseling for older men. J Am Geriatr SoC 2009;57:1166-74.

24 Labour Research Department. Exercise on prescription: a report for the Chartered Society of Physiotherapists. Labour Research Department, 2004

25 Williams NH, Hendry M, France B, Lewis R, Wilkinson C. Effectiveness of exercise-referral schemes to promote physical activity in adults: systematic review. Br J Gen Pract 2007:57:979-86.

26 Harland J, White M, Drinkwater C, Chinn D, Farr L, Howel D. The Newcastle exercise project: a randomised controlled trial of methods to promote physical activity in primary care. BMJ 1999;319:828-32.

27 Chambers R, Chambers C, Campbell I. Exercise promotion for patients with significant medical problems. Health Educ J 2000;59:90-8.

28 The Writing Group for the Activity Counseling Trial Research Group. Effects of physical activity counseling in primary care: the activity counseling trial: a randomized controlled trial. JAMA 2001;286:677-87.

29 Elley CR, Kerse N, Arroll B, Robinson E. Effectiveness of counselling patients on physical activity in general practice: cluster randomised controlled trial. BMJ 2003:326:793.

30 Hillsdon M, Thorogood M, White I, Foster C. Advising people to take more exercise is ineffective: a randomized controlled trial of physical activity promotion in primary care. Int J Epidemiol 2002;31:808-15.

31 Petrella RJ, Koval JJ, Cunningham DA, Paterson DH. Can primary care doctors prescribe exercise to improve fitness?: The step test exercise prescription (STEP) project. Am J Prev Med 2003;24:316-22.

32 Kinmonth AL, Wareham NJ, Hardeman W, Sutton S, Prevost AT, Fanshawe T, et al. Efficacy of a theory-based behavioural intervention to increase physical activity in an at-risk group in primary care (ProActive UK): a randomised trial. Lancet 2008;371:41-8.

33 Higgins JPT, Green S, eds. Cochrane Handbook for Systematic Reviews of Interventions version 5.0.2 (updated September 2009). Chapter 8. Cochrane Collaboration, 2009.

34 Higgins JPT, Green S, eds. Cochrane Handbook for Systematic Reviews of Interventions version 5.0.2 (updated September 2009). Chapter 7 7.3.8. Cochrane Collaboration, 2009.

35 Halbert JA, Silagy CA, Finucane PM, Withers RT, Hamdorf PA. Physical activity and cardiovascular risk factors: effect of advice from an exercise specialist in Australian general practice. Med J Aust 2000;173:84-7.

36 Lamb SE, Bartlett HP, Ashley A, Bird W. Can lay-led walking programmes increase physical activity in middle aged adults? A randomised controlled trial. $J$ Epidemiol Community Health 2002:56:246-52.

37 Higgins JPT, Green S, eds. Cochrane Handbook for Systematic Reviews of Interventions version 5.0.2 (updated September 2009). Chapter 16.3.4. Cochrane Collaboration, 2009.

38 Higgins JP, Thompson SG, Deeks JJ, Altman DG. Measuring inconsistency in meta-analyses. BMJ 2003;327:557-60.

39 McQuay HJ, Moore RA. Using numerical results from systematic reviews in clinical practice. Ann Intern Med 1997:126:712-20. 


\section{What is already known on this topic}

Physical activity promotion in primary care improves self reported physical activity in the short term (3-6 months), but its effect in the longer term is unclear

Exercise referral schemes are popular yet costly, and their effectiveness compared with other types of intervention over the medium to long term is unknown

\section{What this study adds}

Physical activity promotion based in primary care increases self reported physical activity over at least 12 months Few published trials exist of exercise referral schemes with at least 12 months of follow-up

The available evidence does not show exercise referral schemes to be significantly more effective at increasing physical activity than other, potentially lower cost, approaches

40 Pavey TG, Taylor AH, Fox KR, Hillsdon M, Anokye N, Campbell JL, et al. Effect of exercise referral schemes in primary care on physical activity and improving health outcomes: systematic review and meta-analysis. BMJ 2011;343:d6462.

41 Muller-Riemenschneider F, Reinhold T, Nocon M, Willich SN. Long-term effectiveness of interventions promoting physical activity: a systematic review. Prev Med 2008:47:354-68.

42 Lawlor DA, Hanratty B. The effect of physical activity advice given in routine primary care consultations: a systematic review. J Public Health 2001;23:219-26.

43 Abraham C, Michie S. A taxonomy of behavior change techniques used in interventions. Health Psychol 2008;27:379-87.

44 Garrett S, Elley CR, Rose SB, O'Dea D, Lawton BA, Dowell AC. Are physical activity interventions in primary care and the community cost-effective? A systematic review of the evidence. BrJ Gen Pract 2011:61:125-33.

45 National Institute for Health and Clinical Excellence. Four commonly used methods to increase physical activity: brief interventions in primary care, exercise referral schemes, pedometers and community-based exercise programmes for walking and cycling National Institute for Health and Clinical Excellence, 2006.

\section{Accepted: 29 December 2011}

\section{Cite this as: BMJ 2012;344:e1389}

This is an open-access article distributed under the terms of the Creative Commons Attribution Non-commercial License, which permits use, distribution, and reproduction in any medium, provided the original work is properly cited, the use is non commercial and is otherwise in compliance with the license. See: http://creativecommons.org/licenses/by$\mathrm{nc} / 2.0 /$ and http://creativecommons.org/licenses/by-nc/2.0/legalcode. 


\section{Tables}

\section{Table 1| Study characteristics}

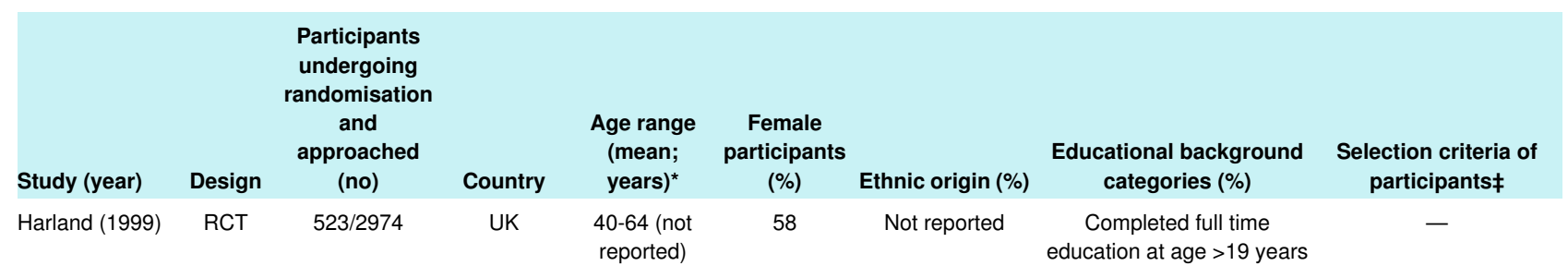

(3), 16 -18 years $(26),<15$ years (71)

\begin{tabular}{|c|c|c|c|c|c|c|c|c|}
\hline & & & & & & & years (71) & \\
\hline $\begin{array}{l}\text { Chambers } \\
(2000)\end{array}$ & $\mathrm{RCT}$ & $454 / 466$ & UK & $19-74 \dagger(61)$ & 46 & Not reported & Not reported & $\begin{array}{l}\text { On practice disease } \\
\text { register for at least one } \\
\text { of the following: } \\
\text { ischaemic heart } \\
\text { disease, stroke, } \\
\text { hypertension, diabetes }\end{array}$ \\
\hline
\end{tabular}

\begin{tabular}{|c|c|c|c|c|c|c|c|c|}
\hline Halbert (2000) & $\mathrm{RCT}$ & $299 / 2878$ & Australia & $\geq 60(67.6)$ & 54 & Not reported & Not reported & - \\
\hline $\begin{array}{l}\text { Activity } \\
\text { CounselingTrial } \\
(2001)\end{array}$ & $\mathrm{RCT}$ & $874 / 3910$ & USA & $35-75$ ( 51.6) & 45 & $\begin{array}{l}\text { White/Asian/other } \\
(72), \text { black (25), } \\
\text { Hispanic (3) }\end{array}$ & $\begin{array}{l}\text { College graduate or higher } \\
\text { education (56), some college } \\
\text { education (28), high school } \\
\text { education or less (16) }\end{array}$ & - \\
\hline Hillsdon (2002) & $\mathrm{RCT}$ & $1658 / 5797$ & UK & $45-64(55)$ & 51 & White (91) & $\begin{array}{l}\text { Higher qualification (10); A } \\
\text { level or equivalent (5); GCSE } \\
\text { or equivalent, or other } \\
\text { qualification (35); no } \\
\text { qualification (45) }\end{array}$ & - \\
\hline
\end{tabular}

\begin{tabular}{|c|c|c|c|c|c|c|c|c|}
\hline Lamb (2002) & $\mathrm{RCT}$ & $260 / 2000$ & UK & $40-70(50.5)$ & 51 & Not reported & Not reported & - \\
\hline Elley (2003) & $\begin{array}{l}\text { Cluster } \\
\text { RCT }\end{array}$ & $878 / 3433$ & $\begin{array}{l}\text { New } \\
\text { Zealand }\end{array}$ & $40-79(57.9)$ & 67 & $\begin{array}{l}\text { European origin } \\
\text { (77) }\end{array}$ & $\begin{array}{l}\text { Post high school qualification } \\
\qquad(26)\end{array}$ & - \\
\hline Petrella (2003) & $\mathrm{RCT}$ & 284/unclear & Canada & $>65(73.5)$ & 48 & Not reported & $\begin{array}{l}\text { Completed education at age } \\
\geq 12 \text { years }(58),<12 \text { years } \\
(42)\end{array}$ & - \\
\hline
\end{tabular}

\begin{tabular}{lllllll}
\hline Harrison (2004) & RCT $\quad 545 / 830 \quad$ UK & $\begin{array}{r}\geq 18 \text { (not } \\
\text { reported) }\end{array}$ & 67 & White (73) & Not reported
\end{tabular}

Three quarters of participants had at least one of the following: obesity, previous myocardial infarction, on ischaemic heart disease register, or diabetes

mellitus

\begin{tabular}{lccccccc}
\hline Jimmy (2005) & RCT & $161 / 571$ & Switzerland & $17-91 \dagger(49)$ & 42 & Not reported & Not reported \\
\hline $\begin{array}{l}\text { Van Sluijs } \\
\text { (2005) }\end{array}$ & $\begin{array}{c}\text { Cluster } \\
\text { RCT }\end{array}$ & $771 / 2377$ & Netherlands & $18-70(55.5)$ & 49 & Not reported & $\begin{array}{c}\text { Educational level: high (20), } \\
\text { medium (43), low (37) }\end{array}$
\end{tabular}

\begin{tabular}{|c|c|c|c|c|c|c|c|c|}
\hline$(2005)$ & $\mathrm{RCT}$ & & 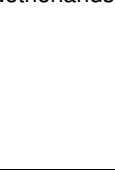 & 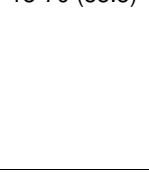 & & & medium (43), low (37) & $\begin{array}{c}\text { hypertension, } \\
\text { hypercholesterolaemia, } \\
\text { type } 2 \text { diabetes mellitus, } \\
\text { or a combination of } \\
\text { these }\end{array}$ \\
\hline Kolt (2007) & $\mathrm{RCT}$ & $186 / 831$ & $\begin{array}{c}\text { New } \\
\text { Zealand }\end{array}$ & $\geq 65(74)$ & 66 & $\begin{array}{l}\text { European origin } \\
(97)\end{array}$ & $\begin{array}{l}\text { University qualification (12), } \\
\text { other post high school } \\
\text { qualification (32), high school } \\
\text { qualification (18), no } \\
\text { qualification (38) }\end{array}$ & - \\
\hline $\begin{array}{l}\text { Kinmonth } \\
(2008)\end{array}$ & $\mathrm{RCT}$ & $365 / 1521$ & UK & $30-50(40.6)$ & 62 & "Generally white" & $\begin{array}{c}\text { Completed full time } \\
\text { education at mean age } 18 \\
\text { years }\end{array}$ & $\begin{array}{c}\text { Adults who had a parent } \\
\text { with type } 2 \text { diabetes } \\
\text { mellitus }\end{array}$ \\
\hline Lawton (2008) & $\mathrm{RCT}$ & $1089 / 5913$ & $\begin{array}{c}\text { New } \\
\text { Zealand }\end{array}$ & $40-74(58.9)$ & 100 & $\begin{array}{l}\text { European } \\
\text { origin(78) }\end{array}$ & Tertiary education (44) & - \\
\hline
\end{tabular}


Table 1 (continued)

\begin{tabular}{|c|c|c|c|c|c|c|c|c|}
\hline Study (year) & Design & $\begin{array}{l}\text { Participants } \\
\text { undergoing } \\
\text { randomisation } \\
\text { and } \\
\text { approached } \\
\text { (no) }\end{array}$ & Country & $\begin{array}{l}\text { Age range } \\
\text { (mean; } \\
\text { years)* }^{*}\end{array}$ & $\begin{array}{c}\text { Female } \\
\text { participants } \\
(\%)\end{array}$ & Ethnic origin (\%) & $\begin{array}{c}\text { Educational background } \\
\text { categories (\%) }\end{array}$ & $\begin{array}{l}\text { Selection criteria of } \\
\text { participants } \ddagger\end{array}$ \\
\hline Morey (2009) & $\mathrm{RCT}$ & 398/3995 & USA & $70-92 \dagger(77.6)$ & 0 & White (77) & $\begin{array}{l}\text { College graduate or higher } \\
\text { education (27); some } \\
\text { college, technical, trade } \\
\text { school education (27); high } \\
\text { school graduate or general } \\
\text { educational development or } \\
\text { lower educational level (46) }\end{array}$ & - \\
\hline
\end{tabular}

RCT=randomised controlled trial.

*Age range of participants eligible for trial inclusion and mean age of participants included in the trial, unless otherwise specified.

†Age range of participants included in the trial.

$\ddagger$ All trials included sedentary adults; characteristics listed are additional selection criteria. 


\begin{tabular}{|c|c|c|c|c|c|}
\hline $\begin{array}{l}\text { Study } \\
\text { (year) }\end{array}$ & Study group & Summary of intervention and control* & $\begin{array}{l}\text { Setting for } \\
\text { intervention } \\
\text { delivery† }\end{array}$ & $\begin{array}{l}\text { Who delivered } \\
\text { intervention† }\end{array}$ & Theoretical approach \\
\hline \multirow[t]{5}{*}{$\begin{array}{l}\text { Harland } \\
(1999)\end{array}$} & Control & $\begin{array}{l}1 \text { feedback session on current health and activity, } \\
\text { information on benefits of physical activity, recommended } \\
\text { physical activity levels, and local leisure centre information }\end{array}$ & GP surgery & Researcher & Not reported \\
\hline & Intervention 1 & Control intervention and 1 motivational interview & $\begin{array}{l}\text { GP surgery, sports } \\
\text { facility }\end{array}$ & Health visitor, researcher & $\begin{array}{l}\text { Motivational } \\
\text { interviewing }\end{array}$ \\
\hline & Intervention 2 & Intervention 1 and 30 leisure centre vouchers & $\begin{array}{l}\text { GP surgery, sports } \\
\text { facility }\end{array}$ & Health visitor, researcher & $\begin{array}{l}\text { Motivational } \\
\text { interviewing }\end{array}$ \\
\hline & Intervention 3 & Control intervention and 6 motivational interviews & $\begin{array}{l}\text { GP surgery, sports } \\
\text { facility }\end{array}$ & Health visitor, researcher & $\begin{array}{l}\text { Motivational } \\
\text { interviewing }\end{array}$ \\
\hline & Intervention 4 & Intervention 3 and 30 leisure centre vouchers & $\begin{array}{l}\text { GP surgery, sports } \\
\text { facility }\end{array}$ & Health visitor, researcher & $\begin{array}{l}\text { Motivational } \\
\text { interviewing }\end{array}$ \\
\hline \multirow{4}{*}{$\begin{array}{l}\text { Chambers } \\
(2000)\end{array}$} & Control & No intervention & - & - & - \\
\hline & Intervention 1 & $\begin{array}{l}1 \text { mailed booklet promoting benefits of exercise with key } \\
\text { messages reinforced in an accompanying letter from GP }\end{array}$ & - & GP & Not reported \\
\hline & Intervention 2 & $\begin{array}{l}\text { Intervention } 1 \text { and } 1 \text { exercise assessment (including } \\
\text { assessment of usual exercise habits, fitness assessment, } \\
\text { and individualised advice on an exercise programme) }\end{array}$ & Not reported & GP, physiotherapist & Not reported \\
\hline & Intervention $3 \ddagger$ & Intervention 2 and 4 exercise sessions in small groups & Not reported & GP, physiotherapist & Not reported \\
\hline \multirow[t]{2}{*}{$\begin{array}{l}\text { Halbert } \\
(2000)\end{array}$} & Control & $\begin{array}{l}1 \text { written information leaflet on good nutrition for older } \\
\text { adults, with subsequent discussion }\end{array}$ & GP surgery & Exercise specialist & Not reported \\
\hline & Intervention & $\begin{array}{c}1 \text { session comprising individualised advice (about benefits } \\
\text { of exercise, discussion about the barriers to exercise, } \\
\text { written physical activity goal), and } 2 \text { follow-up sessions to } \\
\text { discuss progress }\end{array}$ & GP surgery & Exercise specialist & Not reported \\
\hline \multirow[t]{3}{*}{$\begin{array}{l}\text { Activity } \\
\text { Counseling } \\
\text { Trial (2001) }\end{array}$} & Control & $\begin{array}{l}\geq 1 \text { physician advice session based on national } \\
\text { recommendations for physical activity, } \geq 1 \text { brief advice } \\
\text { session with health educator, and educational materials }\end{array}$ & Primary care & $\begin{array}{l}\text { Primary care physician, } \\
\text { health educator }\end{array}$ & Not reported \\
\hline & Intervention 1 & $\begin{array}{l}\geq 1 \text { physician advice session, } \geq 1 \text { behavioural counselling } \\
\text { session, } 1 \text { telephone advice or support call, educational } \\
\text { materials, monthly newsletters, and self-monitoring tools }\end{array}$ & Primary care & $\begin{array}{l}\text { Primary care physician, } \\
\text { health educator }\end{array}$ & Social cognitive theory \\
\hline & Intervention 2 & $\begin{array}{l}\text { Intervention } 1 \text { and regular telephone counselling over } 2 \\
\text { years }\end{array}$ & Primary care & $\begin{array}{l}\text { Primary care physician, } \\
\text { health educator }\end{array}$ & Social cognitive theory \\
\hline \multirow{3}{*}{$\begin{array}{l}\text { Hillsdon } \\
\text { (2002) }\end{array}$} & Control & No intervention & - & - & - \\
\hline & Intervention 1 & $\begin{array}{l}1 \text { baseline health check (comprising motivational interview } \\
\text { and measurement of blood pressure and weight), } 6 \\
\text { telephone calls using motivational interview techniques, } \\
1 \text { follow-up health check, and self monitoring tools }\end{array}$ & Primary care & $\begin{array}{l}\text { Health promotion } \\
\text { specialist }\end{array}$ & $\begin{array}{l}\text { Motivational } \\
\text { interviewing }\end{array}$ \\
\hline & Intervention 2 & $\begin{array}{l}\text { As per intervention 1, but advice given on physical activity } \\
\text { in lieu of motivational interview techniques }\end{array}$ & Primary care & $\begin{array}{l}\text { Health promotion } \\
\text { specialist }\end{array}$ & Health belief model \\
\hline \multirow[t]{2}{*}{$\begin{array}{l}\text { Lamb } \\
(2002)\end{array}$} & Control & $\begin{array}{l}1 \text { group advice session (including health benefits of } \\
\text { exercise and recommended activity levels) and written } \\
\text { guidance }\end{array}$ & Primary care & Physiotherapist & Not reported \\
\hline & Interventionł & $\begin{array}{l}\text { Referral to health walks programme, } \leq 3 \text { telephone calls } \\
\text { encouraging participation, written information on self led } \\
\text { walks, and control intervention }\end{array}$ & Primary care & Physiotherapist & Not reported \\
\hline \multirow{2}{*}{$\begin{array}{l}\text { Elley } \\
(2003)\end{array}$} & Control & No intervention & - & - & - \\
\hline & Intervention & $\begin{array}{c}1 \text { advice session with primary care clinician using } \\
\text { motivational interview techniques, written exercise } \\
\text { prescription, } \geq 3 \text { support phone calls, quarterly newsletters, } \\
\text { and other mailed motivational materials }\end{array}$ & GP surgery & $\begin{array}{c}\text { GP or practice nurse, } \\
\text { exercise specialist }\end{array}$ & $\begin{array}{l}\text { Motivational } \\
\text { interviewing }\end{array}$ \\
\hline \multirow[t]{2}{*}{$\begin{array}{l}\text { Petrella } \\
(2003)\end{array}$} & Control & $\begin{array}{l}1 \text { counselling session with doctor (including discussion of } \\
\text { benefits of exercise and national guidelines), written } \\
\text { details of local exercise facilities, and self monitoring tools }\end{array}$ & $\begin{array}{l}\text { Family medicine } \\
\text { clinic }\end{array}$ & Primary care physician & Not reported \\
\hline & Intervention & $\begin{array}{l}\text { Control intervention and prescription of exercise heart rate } \\
\text { on } 3 \text { occasions by doctor }\end{array}$ & $\begin{array}{l}\text { Family medicine } \\
\text { clinic }\end{array}$ & Primary care physician & Not reported \\
\hline $\begin{array}{l}\text { Harrison } \\
(2004)\end{array}$ & Control & $\begin{array}{l}\text { Mailed information (with benefits of physical activity, list } \\
\text { of local exercise facilities, and telephone number for } \\
\text { specific queries) }\end{array}$ & - & - & - \\
\hline
\end{tabular}


Table 2 (continued)

\begin{tabular}{|c|c|c|c|c|c|}
\hline $\begin{array}{l}\text { Study } \\
\text { (year) }\end{array}$ & Study group & Summary of intervention and control ${ }^{\star}$ & $\begin{array}{l}\text { Setting for } \\
\text { intervention } \\
\text { deliveryt }\end{array}$ & $\begin{array}{l}\text { Who delivered } \\
\text { intervention† }\end{array}$ & Theoretical approach \\
\hline & Interventionł & $\begin{array}{l}\text { Control intervention, referral by primary care doctor to } \\
\text { leisure centre based exercise programme; } 1 \text { face to face } \\
\text { advice session; } 12 \text { weeks' subsidised use of leisure } \\
\text { centre, and } 1 \text { follow-up session to review progress }\end{array}$ & Leisure centre & Exercise officer & Not reported \\
\hline \multirow[t]{2}{*}{$\begin{array}{l}\text { Jimmy } \\
(2005)\end{array}$} & Control & $\begin{array}{l}1 \text { feedback session with GP on current stage of change } \\
\text { related to international physical activity guidelines }\end{array}$ & GP office & GP & Transtheoretical model \\
\hline & Intervention & $\begin{array}{l}\text { Control intervention, stage specific leaflet, offer of } 1 \\
\text { participant subsidised counselling session, and } 3 \text { follow-up } \\
\text { telephone calls }\end{array}$ & GP office & $\begin{array}{l}\text { GP, physical activity } \\
\text { specialist }\end{array}$ & Transtheoretical model \\
\hline \multirow[t]{2}{*}{$\begin{array}{l}\text { Van Sluijs } \\
(2005)\end{array}$} & Control & $\begin{array}{c}1 \text { brief advice session with clinician recommending } \\
\text { increased physical activity }\end{array}$ & GP surgery & GP or practice nurse & Not reported \\
\hline & Intervention & $\begin{array}{c}1 \text { stage specific counselling session on physical activity } \\
\text { with primary care clinician written exercise prescription, } \\
1 \text { follow-up counselling session with primary care clinician } \\
\text { and } 2 \text { telephone support calls }\end{array}$ & GP surgery & $\begin{array}{l}\text { GP or practice nurse, } \\
\text { trained physical activity } \\
\text { counsellor }\end{array}$ & $\begin{array}{l}\text { Transtheoretical model } \\
\text { and social cognitive } \\
\text { theory }\end{array}$ \\
\hline \multirow[t]{2}{*}{ Kolt (2007) } & Control & No intervention & - & - & - \\
\hline & Intervention & $\begin{array}{l}8 \text { counselling sessions by telephone, generic written } \\
\text { information on physical activity, and self monitoring tools }\end{array}$ & - & Exercise counsellor & Transtheoretical model \\
\hline \multirow[t]{3}{*}{$\begin{array}{l}\text { Kinmonth } \\
(2008)\end{array}$} & Control & $\begin{array}{l}\text { Mailed leaflet with brief motivational advice on benefits of } \\
\text { increased physical activity }\end{array}$ & - & - & - \\
\hline & Intervention 1 & $\begin{array}{l}\text { Control intervention, } 5 \text { counselling sessions (designed to } \\
\text { alter behavioural determinants and teach behavioural } \\
\text { change strategies to increase physical activity), and } 9 \\
\text { support telephone calls }\end{array}$ & Home & $\begin{array}{l}\text { Trained facilitator from a } \\
\text { range of health } \\
\text { professions }\end{array}$ & $\begin{array}{l}\text { Theory of planned } \\
\text { behaviour }\end{array}$ \\
\hline & Intervention 2 & $\begin{array}{l}\text { Control intervention, } 1 \text { counselling session (as per } \\
\text { intervention 1), } 6 \text { support telephone calls, and } 7 \text { postal } \\
\text { contacts }\end{array}$ & Home & $\begin{array}{l}\text { Trained facilitator from a } \\
\text { range of health } \\
\text { professions }\end{array}$ & $\begin{array}{l}\text { Theory of planned } \\
\text { behaviour }\end{array}$ \\
\hline \multirow{2}{*}{$\begin{array}{l}\text { Lawton } \\
(2008)\end{array}$} & Control & No intervention & - & - & - \\
\hline & Intervention & $\begin{array}{l}2 \text { counselling sessions with primary care nurse (including } \\
\text { motivational interview techniques to promote physical } \\
\text { activity), written exercise prescription, and average of } 5 \\
\text { telephone support calls }\end{array}$ & $\begin{array}{l}\text { Primary care } \\
\text { practice }\end{array}$ & $\begin{array}{l}\text { Primary care nurse, } \\
\text { exercise facilitator }\end{array}$ & $\begin{array}{l}\text { Motivational } \\
\text { interviewing }\end{array}$ \\
\hline \multirow{2}{*}{$\begin{array}{l}\text { Morey } \\
(2009)\end{array}$} & Control & No intervention & - & - & - \\
\hline & Intervention & $\begin{array}{l}1 \text { counselling session, about } 12 \text { counselling telephone } \\
\text { calls, about } 12 \text { automatic telephone messages, } 1 \\
\text { endorsement of physical activity by primary care provider, } \\
\text { self monitoring tools, and } 4 \text { written progress reports }\end{array}$ & Primary care & $\begin{array}{l}\text { Primary care provider, } \\
\text { health counsellor }\end{array}$ & $\begin{array}{l}\text { Transtheoretical model } \\
\text { and social cognitive } \\
\text { theory }\end{array}$ \\
\hline
\end{tabular}

GP=general practitioner.

*All advice or counselling sessions and motivational interviews relate to physical activity and were delivered in person on a one to one basis, unless otherwise specified.

†For intervention components delivered in person.

$\ddagger$ Exercise referral intervention. 


\begin{tabular}{|c|c|c|c|c|c|c|}
\hline \multirow[b]{2}{*}{ Study (year) } & \multicolumn{6}{|c|}{ Risk of bias } \\
\hline & $\begin{array}{c}\text { Sequence generation } \\
\text { (randomisation } \\
\text { method)* }\end{array}$ & $\begin{array}{c}\text { Allocation } \\
\text { concealment } †\end{array}$ & $\begin{array}{l}\text { Blinding of } \\
\text { participants to study } \\
\text { group allocation } \neq\end{array}$ & $\begin{array}{c}\text { Blinding of trial } \\
\text { personnel or } \\
\text { outcome assessors } \neq\end{array}$ & $\begin{array}{c}\text { Incomplete } \\
\text { outcome data§ }\end{array}$ & $\begin{array}{l}\text { Selective outcome } \\
\text { reportingף }\end{array}$ \\
\hline Harland (1999) & Low & Low & Unclear & Low & Low & Low \\
\hline Chambers (2000) & Low & Unclear & High & Unclear & High & Low \\
\hline Halbert (2000) & Unclear & Low & Unclear & High & High & Low \\
\hline $\begin{array}{l}\text { Activity Counseling Trial } \\
\text { (2001) }\end{array}$ & Low & Low & Unclear & High & Low & Low \\
\hline Hillsdon (2002) & Unclear & Low & High & High & High & Low \\
\hline Lamb (2002) & Unclear & Low & Unclear & Unclear & High & Low \\
\hline Elley (2003) & Low & Low & High & High & Low & Low \\
\hline Petrella (2003) & Low & Low & Unclear & Low & High & Low \\
\hline Harrison (2004) & Low & Low & Unclear & Unclear & High & Low \\
\hline Jimmy (2005) & Unclear & Low & Unclear & Unclear & Low & Low \\
\hline Van Sluijs (2005) & Low & Low & Low & High & Low & Low \\
\hline Kolt (2007) & Low & Low & High & Low & Low & Low \\
\hline Kinmonth (2008) & Low & Low & High & Low & Low & Low \\
\hline Lawton (2008) & Low & Low & High & Low & Low & High \\
\hline Morey (2009) & Low & Low & High & Low & Low & Low \\
\hline
\end{tabular}

*Assessment of whether method used to generate the allocation sequence should produce comparable groups.

†Assessment of whether allocation could have been foreseen in advance of enrolment by participants or recruitment personnel.

$\ddagger$ Assessment of whether knowledge of the allocated intervention was adequately prevented during the study

§Assessment of whether incomplete outcome data were adequately dealt with, including (but not limited to) assessment of attrition rates in included studies.

Studies with missing primary outcome data for $>20 \%$ of participants who underwent randomisation, or with $>5 \%$ difference in attrition rates between intervention and control groups, were considered to be at high risk of bias.

ๆAssessment of whether all outcome measures described in introduction and methods section of the paper were reported. 


\begin{tabular}{|c|c|c|c|c|}
\hline Study (year) & Questionnaire or logbook & $\begin{array}{l}\text { Self administered (S) } \\
\text { or interviewer } \\
\text { administered (I) }\end{array}$ & $\begin{array}{l}\text { Period covered by } \\
\text { questionnaire or logbook }\end{array}$ & Validated \\
\hline Harland (1999) & $\begin{array}{c}\text { Shortened version of National Fitness Survey } \\
\text { questionnaire }\end{array}$ & $\mathrm{S}, \mathrm{I}$ & 1 month recall & Not stated or unclear \\
\hline Chambers (2000) & $\begin{array}{c}\text { Questionnaire about exercise frequency and } \\
\text { behaviour }\end{array}$ & $S$ & $\begin{array}{l}1 \text { month recall (frequency), } \\
\text { current (behaviour) }\end{array}$ & Not stated or unclear \\
\hline Halbert (2000) & Questionnaire about physical activity levels & $\mathrm{S}$ & Not stated or unclear & Not stated or unclear \\
\hline $\begin{array}{l}\text { Activity Counseling trial } \\
(2001)\end{array}$ & $\begin{array}{c}7 \text { day Physical Activity Recall (7 day PAR) } \\
\text { questionnaire }\end{array}$ & I & 7 day recall & Yes \\
\hline Hillsdon (2002) & $\begin{array}{l}\text { Physical activity logbook, based on modified version } \\
\text { of Minnesota Leisure Time Activity Questionnaire } \\
\text { (MLTAQ) }\end{array}$ & $\mathrm{S}$ & $\begin{array}{c}\text { Prospective recording over } 28 \\
\text { days }\end{array}$ & Not stated or unclear \\
\hline Lamb (2002) & $\begin{array}{c}\text { Physical activity questionnaire, based on Stanford } 5 \\
\text { Cities questionnaire }\end{array}$ & S & 7 day recall & $\begin{array}{l}\text { Based on validated } \\
\text { instrument }\end{array}$ \\
\hline Elley (2003) & Physical activity questionnaire & $\mathrm{S}$ & 3 month recall & Yes \\
\hline Petrella (2003) & Self reported activity not measured & Not applicable & Not applicable & Not applicable \\
\hline Harrison (2004) & $\begin{array}{c}\text { Version of } 7 \text { day Physical Activity Recall (7 day PAR) } \\
\text { questionnaire }\end{array}$ & S & 7 day recall & $\begin{array}{l}\text { Based on validated } \\
\text { instrument }\end{array}$ \\
\hline Jimmy (2005) & Physical activity questionnaire & $\mathrm{S}, \mathrm{I}$ & 7 day recall & Yes \\
\hline Van Sluijs (2005) & $\begin{array}{l}\text { Short Questionnaire to Assess Health-enhancing } \\
\text { physical activity (SQUASH) }\end{array}$ & Not stated or unclear & $\begin{array}{l}\text { Recall of average week in past } \\
\text { month }\end{array}$ & Yes \\
\hline Kolt (2007) & $\begin{array}{l}\text { Auckland Heart Study Physical Activity Questionnaire } \\
\text { (AHSPAQ) }\end{array}$ & I & 3 month recall & Yes \\
\hline Kinmonth (2008) & $\begin{array}{l}\text { EPIC-Norfolk Physical Activity Questionnaire } \\
\text { (EPAQ2) }\end{array}$ & S & 12 month recall & Yes \\
\hline Lawton (2008) & $\begin{array}{l}\text { Long form of the New Zealand physical activity } \\
\text { questionnaire (NZPAQ-LF) }\end{array}$ & Not stated or unclear & 7 day recall & Yes \\
\hline Morey (2009) & $\begin{array}{l}\text { Community Health Activities Model Program for } \\
\text { Seniors (CHAMPS) physical activity questionnaire }\end{array}$ & Not stated or unclear & Not stated or unclear & Yes \\
\hline
\end{tabular}




\section{Figures}

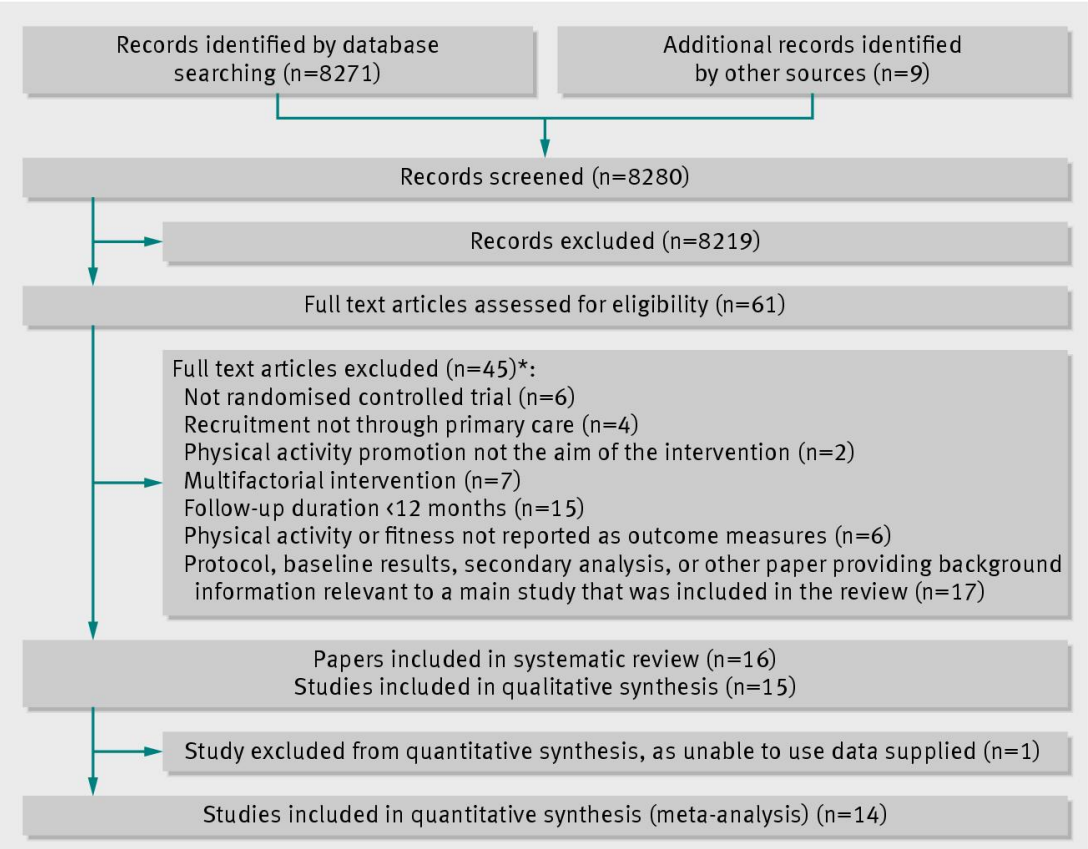

Fig 1 Study selection flow diagram. *Each paper might have more than one reason for exclusion
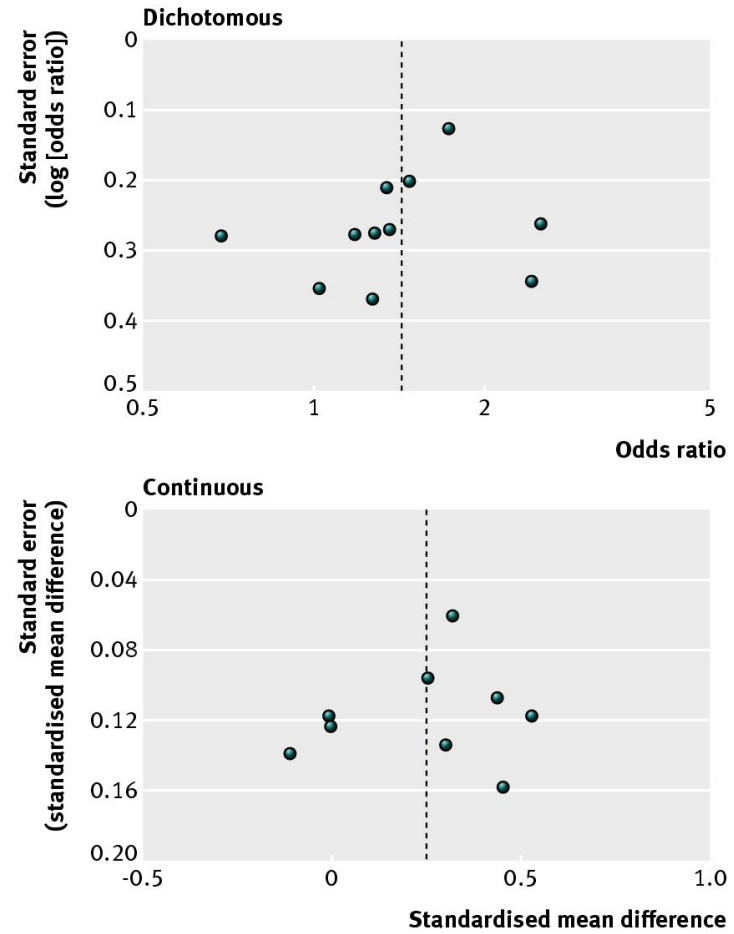

Fig 2 Funnel plots comparing interventions of physical activity promotion with control interventions for studies reporting dichotomous or continuous outcome data on self reported physical activity 
Study

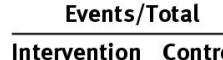

\begin{tabular}{|c|c|c|c|c|c|c|}
\hline 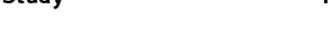 & 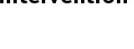 & & $(95 \%$ & $\%$ (I), IV & (\%) & $(95 \% \mathrm{CI}), \mathrm{IV}$ \\
\hline Van Sluijs 2005 & $47 / 97$ & $64 / 111$ & & & 8.2 & 0.69 (0.40 to 1.19$)$ \\
\hline Jimmy 2005 & $26 / 55$ & $36 / 77$ & & & 5.9 & $1.02(0.51$ to 2.04$)$ \\
\hline Harland 1999 & $92 / 351$ & $21 / 91$ & & & 8.3 & 1.18 (0.69 to 2.04$)$ \\
\hline Chambers 2000 & $42 / 231$ & $11 / 74$ & & & 5.6 & $1.27(0.62$ to 2.62$)$ \\
\hline Lamb 2002 & $40 / 129$ & $34 / 131$ & & & 8.4 & $1.28(0.75$ to 2.20$)$ \\
\hline Elley 2003 & $73 / 226$ & $56 / 214$ & & & 11.3 & 1.35 (0.89 to 2.03) \\
\hline Harrison 2004 & $40 / 155$ & $32 / 157$ & & & 8.6 & $1.36(0.80$ to 2.31$)$ \\
\hline Activity Counseling Trial 2001 & $114 / 535$ & $41 / 265$ & & & 11.9 & $1.48(1.00$ to 2.19$)$ \\
\hline Lawton 2008 & $233 / 544$ & $165 / 545$ & & & 16.7 & $1.73(1.34$ to 2.21$)$ \\
\hline Kolt 2007 & $35 / 83$ & $19 / 82$ & & 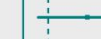 & 6.2 & $2.42(1.23$ to 4.74$)$ \\
\hline Morey 2009 & $57 / 178$ & $28 / 177$ & & & 8.9 & 2.51 (1.50 to 4.18$)$ \\
\hline Total $(95 \% \mathrm{Cl})$ & $799 / 2584$ & $507 / 1924$ & & $<$ & 100.0 & $1.42(1.17$ to 1.73$)$ \\
\hline $\begin{array}{l}\text { Test for heterogeneity: } \tau \\
P=0.06,\left.\right|^{2}=43 \%\end{array}$ & $x^{2}=17.50$ & $d f=10$, & $0.2 \quad 0.5$ & 1 & 5 & \\
\hline
\end{tabular}

Fig 3 Individual study and pooled effects of physical activity promotion on self reported physical activity at 12 months (dichotomous data). Random effects model used. 95\% Cl=95\% confidence intervals; IV=inverse variance

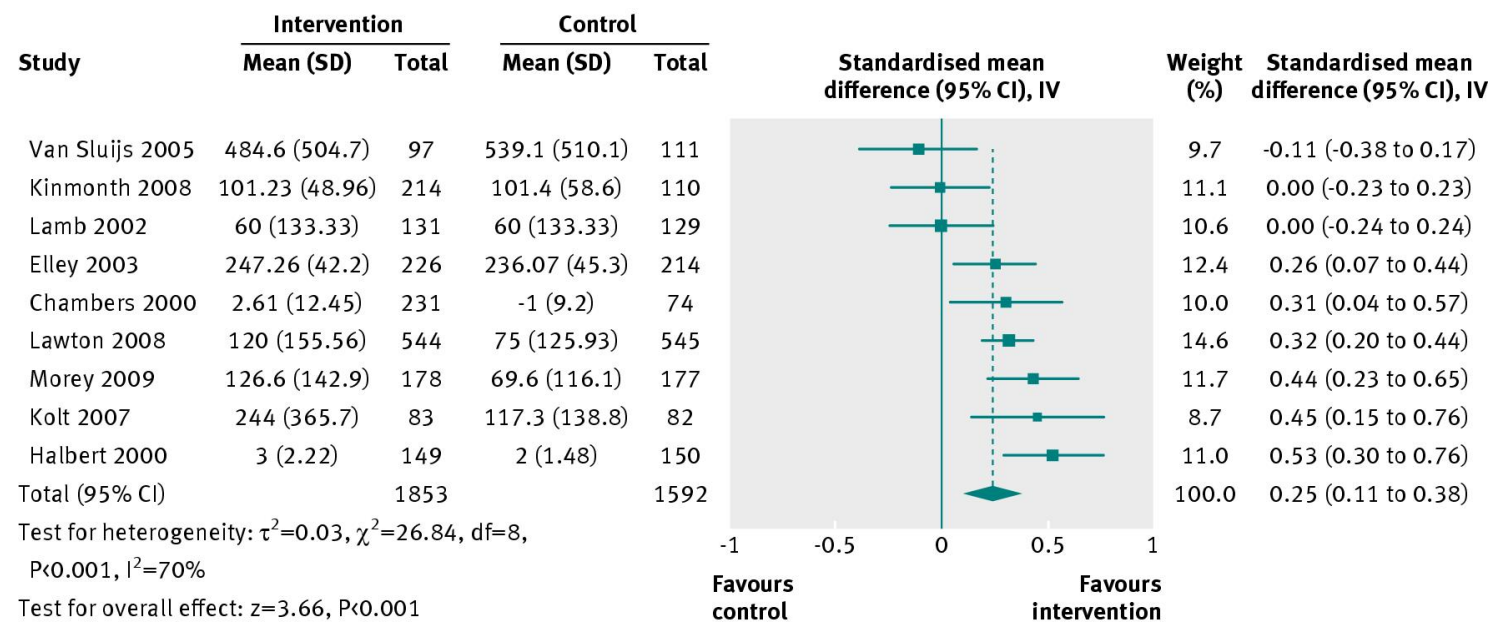

Fig 4 Individual study and pooled effects of physical activity promotion on self reported physical activity at 12 months (continuous data). Random effects model used. SD=standard deviation; $95 \% \mathrm{Cl}=95 \%$ confidence intervals; IV=inverse variance

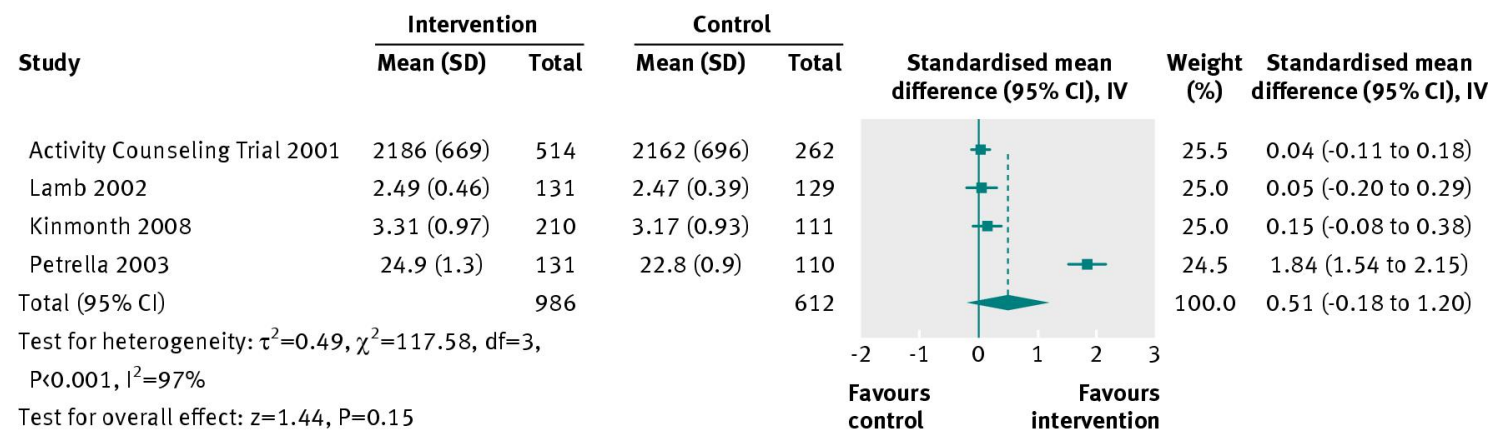

Fig 5 Individual study and pooled effects of physical activity promotion on cardiorespiratory fitness at 12 months. Random effects model used. SD=standard deviation; $95 \% \mathrm{Cl}=95 \%$ confidence intervals; IV=inverse variance 


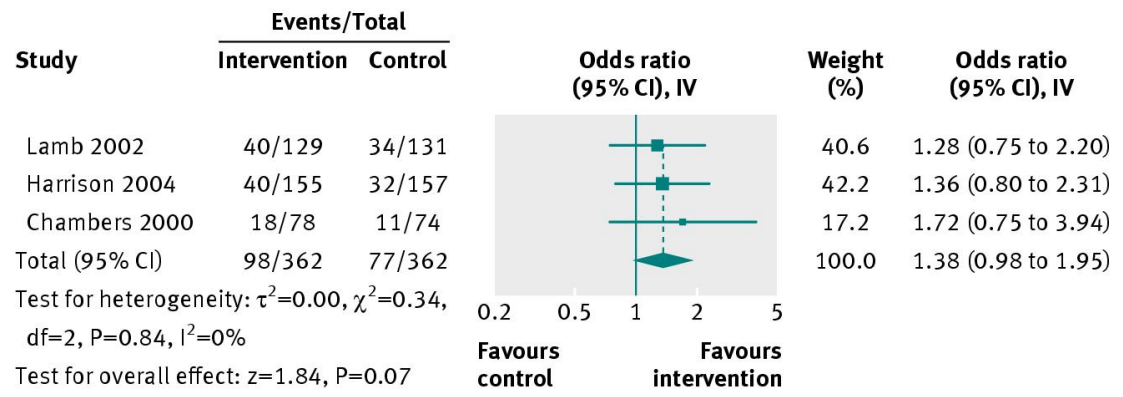

Fig 6 Individual study and pooled effects of physical activity promotion on self reported physical activity at 12 months, exercise referral interventions only (dichotomous data). Random effects model used. $95 \% \mathrm{Cl}=95 \%$ confidence intervals; $\mathrm{IV}=$ inverse variance

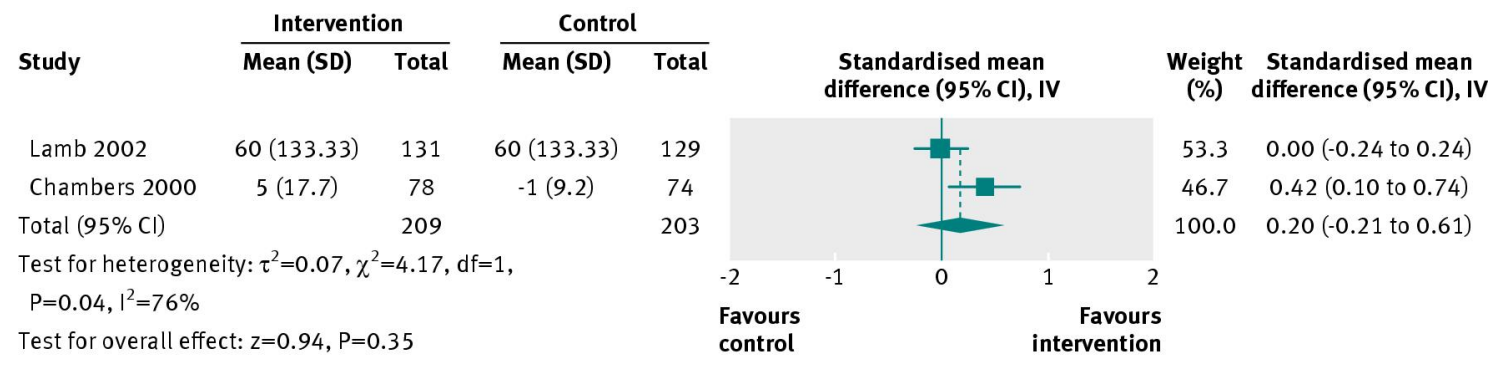

Fig 7 Individual study and pooled effects of physical activity promotion on self reported physical activity at 12 months, exercise referral interventions only (continuous data). Random effects model used. SD=standard deviation; $95 \% \mathrm{Cl}=95 \%$ confidence intervals; IV=inverse variance

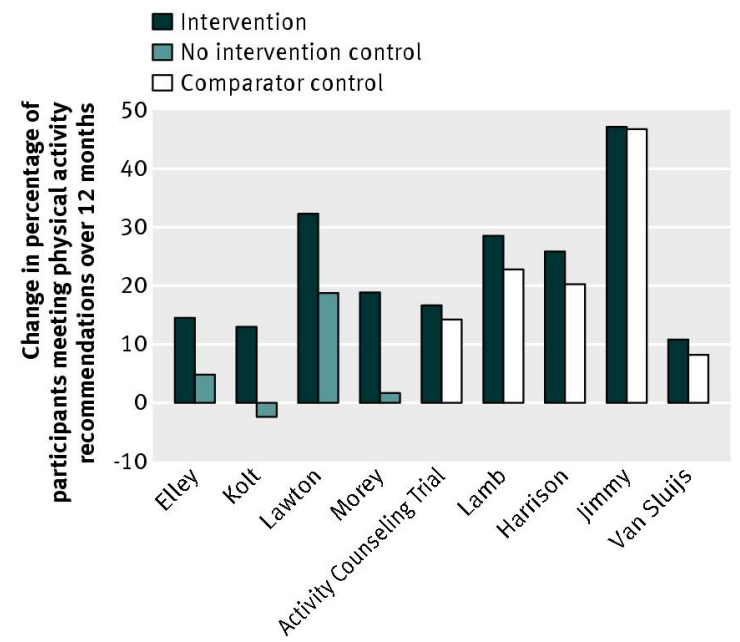

Fig 8 Change in percentage of participants meeting physical activity recommendations between baseline and 12 months of follow-up. Recommendations involved $\geq 150 \mathrm{~min} /$ week physical activity of moderate intensity, for all studies apart from Lamb ( $\geq 120 \mathrm{~min} /$ week activity of moderate intensity) and Harrison ( $\geq 90 \mathrm{~min} /$ week activity of moderate intensity). The Jimmy study and the Activity Counseling Trial had 14 and 24 months of follow-up, respectively 